ISSN 1112-9867

http://www.jfas.info

\title{
ESTIMATING OCTANOL/WATER PARTITION COEFFICIENT FOR SELECTED FERROCENE DERIVATIVES USING XLOGPV2.0 APPROACH
}

\author{
R. Ahmedi*, T. Lanez \\ University of El Oued, VTRS Laboratory, Faculty of exact Sciences, B.P.789, 39000, El Oued, \\ Algeria
}

Received: 08 August 2016 / Accepted: 24 August 2016 / Published online: 01 September 2016

\begin{abstract}
Octanol/water partition coefficients $\mathrm{P}$ of several substituted ferrocene were calculated on the basis of the adaptation of the existing XlogPv2.0 approach. The predicted of calculated partition coefficients values of $\log \mathrm{P}$ for selected ferrocene derivatives was compared with known experimental values taken from literature. The shown Results confirmed that the calculated partition coefficients were in good accord with experimental values. The average of absolute error is 0.12 , and the obtained correlation coefficient value $\mathrm{R}^{2}$ for the linear dependencies between experimental and calculated partitions coefficients is 0.977 .
\end{abstract}

Keywords: Experimental $\log$, theoretical partition coefficient, ferrocene derivatives, lipophilicity, QSAR.

Author Correspondence, e-mail: ahmedi258@gmail.com

doi: http://dx.doi.org/10.4314/jfas.v8i3.29

\section{INTRODUCTION}

Octanol-water partition coefficient $\mathrm{P}$ generally expressed as $\log \mathrm{P}$ is fundamental physicochemical phenomenon, that extensively describe a chemical lipophilic or hydrophobic properties, is defined as the rapport of the molar concentration of a chemical dissolved at 
equilibrium in octanol phase to its molar concentration in aqueous phase [1],it's used in many scientific area such as analytical chemistry, environmental science, in the assessment of environmental fate and transport of organic chemicals, pharmaceutical research such as drug design and toxicological sciences [2-5], successful applications in quantitative structure activity relationships (QSAR), it is considered a required property in studies of new or undesired chemicals.

Previously, the estimation of $\log \mathrm{P}$ of several substituted ferrocene using three different methods, Rekker, XlogPand AlogP has been reported[6-9].

We herein present a simple approach for the predition of n-octanol/water partition coefficients of a series of eleven ferrocene derivatives using theoretical calculations on the basis of the adaptation of the existing XlogPv2.0 approach, the XlogP's improved method.

\section{MATERIALS AND METHODS}

This section explains the generation of our model of calculation of $\log \mathrm{P}$ of substituted ferrocene. This calculation is based upon the adaptation of the exciting atom-additive XlogPv2.0 method, which considers the partition molecular species between an aqueous phase and an organic phase, in our case is octanol.

\subsection{Principle of the xlogpv2.0 approach}

Atom-additive XlogPv2.0 method gives $\log \mathrm{P}$ values by summing the contributions of component atoms and correction factors [10] equation (1).

$$
\log \mathrm{P}=\sum \mathrm{C}_{\mathrm{i}} \mathrm{a}_{\mathrm{i}}+\sum \mathrm{d}_{\mathrm{j}} \mathrm{D}_{\mathrm{j}}
$$

Where ci and $\mathrm{dj}$ are regression coefficients, $\mathrm{Ci}$ is the number of occurrences of the ith atom type, and $\mathrm{Dj}$ is the number of occurrences of the jth correction, there are 100 terms in this equation (90 atom types plus 10 correction factors). The atom type can be obtained by classifying atoms according to their number of attached hydrogen atoms, hybridization states and their neighbouring atoms.

\subsection{Adaptation and simulation of the xlogpv2.0 approach}

In order to adapt XlogPv2.0 approach to n-octanol/water partition coefficient of ferrocene derivatives, the following approximation should be made; firstly the ferrocene molecule does 
not contain any hydrogen bonding or any interaction which can affect its value. LogP value of ferrocene by XlogPv2.0 method should be equal to the measured value of $\log P$ of ferrocene itself, which is equal to 2.66 [11]. The calculation can be carried out as follows, according to $\mathrm{X} \log \mathrm{Pv} 2.0$ method, the contribution of an aromatic carbon atom attached to any type of carbon symbolised by $c_{c_{a r}-c}$ is less than the contribution of an aromatic carbon atom attached to a hydrogen atom $a_{c_{a r}-H}$, and the difference can be calculated as follows:

$$
c_{c_{a r}-c-} c_{c_{a r}-H}=0.296-0.337=-0.041
$$

The contribution of an aromatic carbon atom attached to an atom of type $X(O, N, S, P, \ldots)$ symbolised as $c_{c_{a r}-X}$ is less than the contribution of an aromatic carbon atom attached to a hydrogen atom symbolised as $c_{c_{a r}-H}$, the difference can also be calculated as indicated by the following equation (3),

$$
c_{c_{a r}-X-} c_{c_{a r}-H}=-0.151-0.337=-0.488
$$

To calculate the contribution of a ferrocenyl group attached to a carbon atom or an atom of type $\mathrm{X}$, the obtained values of -0.041 and -0.488 should be subtracted to $\log \mathrm{P}$ value of ferrocene and the contributions of the attached hydrogen atoms are included in atom type, were subtracted as indicated by equations (2)and(3), as follows

$$
\mathrm{c}_{F C}=\log P_{F C}-n_{1}(0.041)-n_{2}(0.488)
$$

$n_{1}$ number of substituents attached to the ferrocenyl group via a carbon atom, $n_{2}$ number of substituents attached to the ferrocenyl group via an heteroatom, with $0 \leq n_{1}+n_{2} \leq 10$, the contribution of a ferrocenyl group attached to an atom of type $\mathrm{X}$ is calculated from equation 4 , $n_{1}$ in this case is equal to zero and $n_{2}$ is equal to 1 .

$$
\begin{gathered}
c_{F C}=\log P_{F C}-0.488 \\
2.66-0.488=2.172
\end{gathered}
$$

If a ferrocenyl group is attached to a carbon atom, its contribution is calculated from the same equation 4 ; with $n_{2}$ in this case is equal to zero.

$$
\begin{gathered}
\mathrm{c}_{F C}=\log P_{F C}-0.041 \\
2.66-0.041=2.619
\end{gathered}
$$


$\log$, for any ferrocene derivatives of type $F c-X^{\prime}$, is therefore can be calculated by summing the contributions of a substituent $X$ 'atom type to the contribution of a ferrocenyl group plus the constitutive (correction factors) terms: as given by the following equation:

$$
\log \mathrm{P}_{F c-X^{\prime}}=c_{F c}+c_{\mathrm{X}^{\prime}}+\sum d_{j} D_{j}
$$

\section{RESULTS AND DISCUSSION}

\subsection{Calculation and validation of the method}

Our method for the prediction of $\log \mathrm{P}$ for substituted ferrocene is validated using eleven different ferrocene derivatives (mainly selected from literature sources) [12-15]. Calculations were carried out in three decimals, with the final result rounded to two decimals.

1. Phenylferrocene (1)

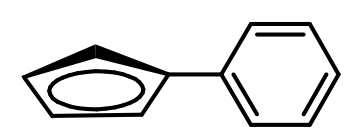

$\mathrm{Fe}$

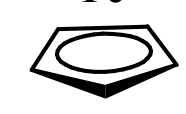

$\log \mathrm{P}$ of this ferrocene derivatives is calculated according to equation 7 as follows:

Table1. Calculation method of $\log P$ for compound (1)

\begin{tabular}{|c|c|c|c|}
\hline Atom type & $\mathrm{C}_{\mathrm{i}}$ & $\mathrm{c}_{\mathrm{i}}$ & $\mathrm{c}_{\mathrm{i}} \times \mathrm{C}_{\mathrm{i}}$ \\
\hline$c_{F c}$ & 1 & 2.619 & 2.619 \\
\hline$c_{C}(34)$ & 1 & 0.296 & 0.296 \\
\hline$c_{C}(32)$ & 5 & 0.337 & 1.685 \\
\hline \multicolumn{2}{|c|}{$d_{j} \times D_{j}$} & - & - \\
\hline \multicolumn{3}{|c|}{$\log P_{c a l .}$} & 4.60 \\
\hline
\end{tabular}

\section{2. $\mathrm{N}$-(ferrocenyl)-isobutyamide (2)}

Ferrocene derivatives with saturated aliphatic hydrocarbon chains carrying functionalized group, we propose no correction for these types of compounds. LogP is calculated using the same equation $7, \log \mathrm{P}$ of this compound is calculated as follows, 


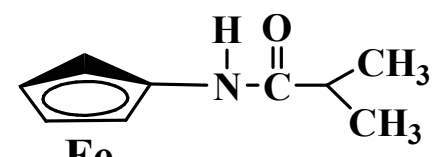

$\mathrm{Fe}$

$\mathrm{CH}_{3}$

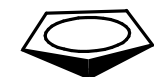

Table2. Calculation method of $\log P$ for compound (2)

\begin{tabular}{|c|c|c|c|}
\hline Atom type & $\mathrm{C}_{\mathrm{i}}$ & $\mathrm{c}_{\mathrm{i}}$ & $\mathrm{c}_{\mathrm{i}} \times \mathrm{C}_{\mathrm{i}}$ \\
\hline$c_{F C}$ & 1 & 2.172 & 2.172 \\
\hline$c_{C}(1)$ & 2 & 0.528 & 1.056 \\
\hline$c_{N}(55)$ & 1 & -0.096 & -0.096 \\
\hline$c_{C}(11)$ & 1 & -0.243 & -0.243 \\
\hline$c_{O}(75)$ & 1 & -0.399 & -0.399 \\
\hline$c_{C}(29)$ & 1 & -0.027 & -0.027 \\
\hline \multicolumn{2}{|c|}{$d_{j} \times D_{j}$} & - & - \\
\hline \multicolumn{2}{|c|}{$\log P_{c a l .}$} & 2.46 \\
\hline
\end{tabular}

3. N-[4-nitro-3-trifluoromethyl-phenyl]-ferrocenecarboxamide (3)

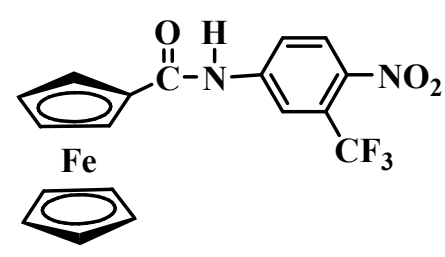

Ferrocene with a basic fragment linked to two aromatic rings is described in this compound, $\log \mathrm{P}$ is obtained by summing the atom types of each group in the molecule and the correction factor for halogen 1-3 pair $I_{H a l}$.

Table3. Calculation method of $\log \mathrm{P}$ for compound (3)

\begin{tabular}{|c|c|c|c|}
\hline Atom type & $\mathrm{C}_{\mathrm{i}}$ & $\mathrm{c}_{\mathrm{i}}$ & $\mathrm{c}_{\mathrm{i}} \times \mathrm{C}_{\mathrm{i}}$ \\
\hline$c_{F c}$ & 1 & 2.619 & 2.619 \\
\hline$c_{N}(55)$ & 1 & -0.096 & -0.096 \\
\hline$c_{C}(29)$ & 1 & -0.030 & -0.030 \\
\hline$c_{O}(75)$ & 1 & -0.399 & -0.399 \\
\hline$c_{C}(32)$ & 3 & 0.337 & 1.011 \\
\hline$c_{C}(34)$ & 1 & 0.296 & 0.296 \\
\hline$c_{C}(35)$ & 2 & -0.151 & -0.302 \\
\hline$c_{C}(20)$ & 1 & -0.723 & -0.723 \\
\hline$c_{F}(83)$ & 3 & 0.375 & 1.125 \\
\hline$c_{N O_{2}}(66)$ & 1 & 1.178 & 1.178 \\
\hline \multicolumn{2}{|c|}{$\log P_{j} \times D_{j}$} & $0.137 \times 3$ & 0.411 \\
\hline \multicolumn{4}{|c|}{} \\
\hline
\end{tabular}


4. N-[4-cyano-3-trifluoromethylphenyl]-ferrocenecarboxamide (4)

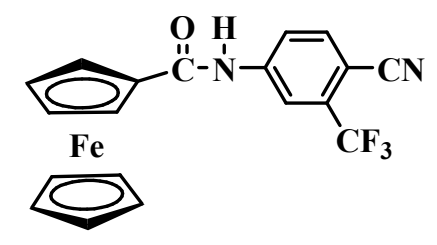

LogP of this ferrocene derivative can be obtained as follows:

Table4. Calculation method of $\log \mathrm{P}$ for compound (4)

\begin{tabular}{|c|c|c|c|}
\hline Atom type & $\mathrm{C}_{\mathrm{i}}$ & $\mathrm{c}_{\mathrm{i}}$ & $\mathrm{c}_{\mathrm{i}} \times \mathrm{C}_{\mathrm{i}}$ \\
\hline$c_{F C}$ & 1 & 2.619 & 2.619 \\
\hline$c_{N}(55)$ & 1 & -0.096 & -0.096 \\
\hline$c_{C}(29)$ & 1 & -0.027 & -0.027 \\
\hline$c_{O}(75)$ & 1 & -0.399 & -0.399 \\
\hline$c_{C}(32)$ & 3 & 0.337 & 0.337 \\
\hline$c_{C}(34)$ & 2 & 0.296 & 0.592 \\
\hline$c_{C}(35)$ & 1 & -0.151 & -0.151 \\
\hline$c_{C}(20)$ & 1 & -0.723 & -0.723 \\
\hline$c_{F}(83)$ & 3 & 0.375 & 1.125 \\
\hline$c_{C N}$ & 1 & -0.566 & -0.566 \\
\hline$c_{C}(39)$ & 1 & 0.330 & 0.330 \\
\hline \multicolumn{2}{|l|}{$d_{j} \times D_{j}$} & $0.137 \times 3$ & 0.411 \\
\hline \multicolumn{3}{|c|}{$\log P_{\text {cal. }}$} & 4.13 \\
\hline
\end{tabular}

5.4'-ferrocényl-1',4'-[bis-(2-trifluorométhyl-1-cyano-phényl)]-2',5'-imidazolidinedione (9)<smiles>N#Cc1ccc(N2C(=O)NC(c3ccccc3)(c3ccccc3)C2=O)cc1C(F)(F)F</smiles>

Ferrocene linked to a direct heterocyclic ring, we propose for these type of molecules a correction factor of 0.580 correction factor for the $\mathrm{sp}^{2}$ oxygen $1-5$ pair $\left(\mathrm{I}_{\mathrm{O}}\right)$ and 0.137 correction factor for each halogen 1-3 pair $\left(I_{H a l}\right), \operatorname{logP}$ is illustrated in table 5. 
Table5. Calculation method of $\log P$ for compound (5)

\begin{tabular}{|c|c|c|c|}
\hline Atom type & $\mathrm{C}_{\mathrm{i}}$ & $\mathrm{c}_{\mathrm{i}}$ & $\mathrm{c}_{\mathrm{i}} \times \mathrm{C}_{\mathrm{i}}$ \\
\hline$c_{F C}$ & 1 & 2.619 & 2.619 \\
\hline$c_{C}(20)$ & 1 & -0.723 & -0.723 \\
\hline$c_{N}(45)$ & 1 & 0.545 & 0.545 \\
\hline$c_{C}(29)$ & 2 & -0.030 & -0.060 \\
\hline$c_{N}(50)$ & 1 & 0.761 & 0.761 \\
\hline$c_{O}(75)$ & 2 & -0.399 & -0.798 \\
\hline$c_{C}(32)$ & 6 & 0.337 & 2.022 \\
\hline$c_{C}(31)$ & 1 & -0.315 & -0.315 \\
\hline$c_{C}(39)$ & 1 & 0.330 & 0.330 \\
\hline$c_{C}(34)$ & 5 & 0.296 & 1.48 \\
\hline$c_{C}(35)$ & 1 & -0.151 & -0.151 \\
\hline$c_{C}(20)$ & 2 & -0.723 & -1.446 \\
\hline$c_{F}(83)$ & 6 & 0.375 & 2.250 \\
\hline$c_{C N}(68)$ & 2 & -0.566 & -1.132 \\
\hline$d_{j} \times D_{j}$ & $0.137 \times 6$ & 0.822 \\
\hline$d_{j} \times D_{j}$ & & 0.580 & 0.580 \\
\hline $\log P_{c a l .}$ & & 6.14 \\
\hline
\end{tabular}

Simillarly as the above $\log \mathrm{P}$ for six ferrocene derivatives (ferrocene in each of those molecule is linked to a direct heterocyclic ring via one or two methylene groups), were calculated from the same equation 7. The results are illustrated in table 6. 


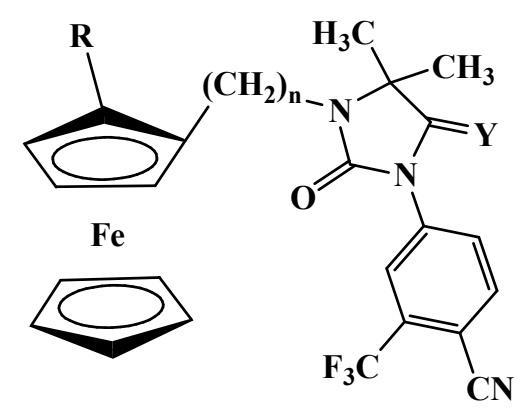

Table6.Calculation method of $\log P$ for six ferrocene derivatives compounds

\begin{tabular}{|c|l|c|c|c|c|}
\hline $\mathrm{N}^{\circ}$ & \multicolumn{1}{|c|}{ Ferrocene derivatives } & $\mathrm{R}$ & $\mathrm{n}$ & $\mathrm{Y}$ & $\log \mathrm{P}_{\text {cal. }}$ \\
\hline 6 & $\begin{array}{l}\text { 4-(4',4'-dimethyl-2',5'-dioxo-3'-ferrocenylmethyl-1'-imidazolidi } \\
\text { nyl)-2-tri fluoromethyl benzonitrile }\end{array}$ & $\mathrm{H}$ & 1 & $\mathrm{O}$ & 5.13 \\
\hline 7 & $\begin{array}{l}\text { 4-(4',4'-dimethyl-2',5'-dioxo-3'-ferrocenylethyl-1'-imidazolidin } \\
\text { yl)-2-tri fluoromethyl-benzonitrile }\end{array}$ & $\mathrm{H}$ & 2 & $\mathrm{O}$ & 5.63 \\
\hline 8 & $\begin{array}{l}\text { (4',4'-Dimethyl-3'-ferrocenylmethyl-5' -imino-2'-oxo-1' } \\
\text { imidazolidinyl) -2- trifluoromethyl-benzonitrile (10) }\end{array}$ & $\mathrm{H}$ & 1 & $\mathrm{NH}$ & 4.67 \\
\hline 9 & $\begin{array}{l}\text { 4',4'-dimethyl-3'-ferrocenylethyl-5'-imino-2'-oxo-1'- } \\
\text { imidazolidinyl)-2- trifluoromethylbenzonitrile (11) }\end{array}$ & $\mathrm{H}$ & 2 & $\mathrm{NH}$ & 5.18 \\
\hline 10 & $\begin{array}{l}\text {-(4',4'-dimethyl-2',5'-dioxo-3'-ferrocenylmethyl-1'-imidazolidin } \\
\text { yl)-2-trifluoromethyl- benzonitrile (7) }\end{array}$ & $\mathrm{CH}_{2} \mathrm{OH}$ & 1 & $\mathrm{O}$ & 4.32 \\
\hline 11 & $\begin{array}{l}\text { 4-[4',4'-dimethyl-2',5'-dioxo-1'-imidazolidinyl-(3'-ortho-metho } \\
\text { xymethyl-ferrocenylmethyl)]-2-trifluoromethyl-benzonitrile (8) }\end{array}$ & $\mathrm{CH}_{2} \mathrm{OCH} 3$ & 1 \\
\hline
\end{tabular}

Obtained values of $\log P$ for the eleven ferrocene derivatives are summarised in table 7 . 
Table7. Calculated $\log \mathrm{P}$ and absolute error results for examined ferrocene derivatives

\begin{tabular}{|c|c|c|c|}
\hline compound & Calculated $\log P_{\text {cal. }}$. & Experimental $\log P_{\text {exp. }}{ }^{*}$ & absolute error $A E^{* *}$ \\
\hline 1 & 4.60 & 4.59 & 0.01 \\
\hline 2 & 2.46 & 2.64 & 0.18 \\
\hline 3 & 4.29 & 4.42 & 0.13 \\
\hline 4 & 4.13 & 4.10 & 0.03 \\
\hline 5 & 6.14 & 6.47 & 0.33 \\
\hline 6 & 5.13 & 5.23 & 0.10 \\
\hline 7 & 5.63 & 5.62 & 0.01 \\
\hline 8 & 4.67 & 4.68 & 0.01 \\
\hline 9 & 5.18 & 5.04 & 0.14 \\
\hline 10 & 4.32 & 4.44 & 0.12 \\
\hline 11 & 4.84 & 5.08 & 0.24 \\
\hline
\end{tabular}

The linear dependencies were received between experimental n-octanol/water partition coefficients and theoretical partition coefficients (Figure.1). The obtained correlation coefficient value for the linear dependencies between partitions coefficients is 0.977 .

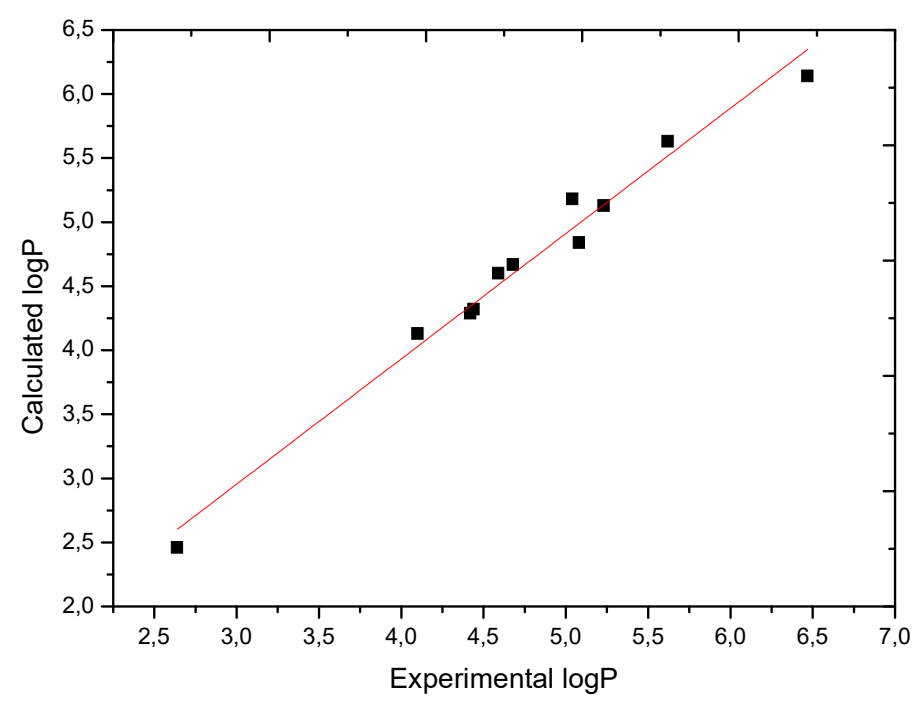

Fig.1. Correlation between experimental and calculated $\log \mathrm{P}$ of substituted ferrocene

\section{CONCLUSION}

In this study, we successfully find a theoretical approach for the estimation of the octanol/water partition coefficients of substituted derivatives. Predictions are based on the expansion of the 
existing XlogPv2.0 approach, we have become able to estimate the partition coefficient of ferrocene derivatives. Values of mesured and theoretical $\log \mathrm{P}$ for several of ferrocene derivatives are in good accord. This approves the process of adaptation.

\section{REFERENCES}

[1] Leo A, Hansch C and Elkins D. Partition Coefficients and Their Uses. Chem. Rev., 1971, 71, 525-616.

[2] Dross K, Mannhold R and Rekker RF. Drug Lipophilicity in QSAR Practice: II. Aspects of RM-Determinations; Critics of RM-Corrections; Interrelations with Partition Coefficients. Quant.Struct-Act. Relat ., 1992, 11,36-44.

[3] KIpczyOska B, Bojarski J, Haber P and KaliszanR. Retention of barbituric acid derivatives on immobilized artificial membrane stationary phase and its correlation with biological activity. Biomed Chromatogr., 2000, 14, 256-60.

[4] Mannhold R and Dross K. Calculation procedures for molecular lipophilicity: a comparative study. Quant. Struct-Act Relat., 1996, 15, 403-9.

[5] Hansch C and Verma RP. A QSAR study for the cytotoxic activities of taxoids against macrophage(MФ)-like cells. Eur. J. Med Chem.,2009, 44,274-79.

[6] Ahmedi R and Lanez T. A new method for the calculation of octanol/water partition coefficients of ferrocene derivatives. Asian. J. Chem., 2010,22, 299-306.

[7] Ahmedi R and Lanez T. A New method for the estimation of octanol/water Partition coefficient of substituted ferrocene using the Atom-additive.Int. J. Pharm.Sci.,2009, 1,183-89.

[8] Ahmedi R and Lanez T. AlogP calculation of octanol/water partition coefficient of ferrocene derivatives. Int.J. PharmTech Res., 2015,8(3), 408-414.

[9] Ahmedi R and Lanez T. Prediction of octanol/water partition coefficient of selected ferrocene derivatives using Rekker method. J. Rev. sci. fond. app., 2011, 3: 57-67.

[10] Renxiao W, Ying G and Luhua L. Calculating partition coefficient by atom-additive method. Perspect Drug .Discov. 2000,19: 47-66.

[11] Leo AJ, The Medicinal Chemistry Project. J.Med.Chem, Pomona College, Claremont, CA 91711., 2000. 
[12] Leo A J. Hydrophobic Parameter Measurement and Calculation, Methods in Enzymologie., 1991, 202, 544-91.

[13] Payen O, Top S, Vessières A, Brulé E, Plamont M, McGlinchey M. J, Müller-Bunz H and Jaouen G. Synthesis and Structure-Activity Relationships of the First Ferrocenyl-Aryl-Hydantoin Derivatives of the Non-steroidal Antiandrogen Nilutamide. J. Med.Chem., 2008, 51,1791-99.

[14] El Arbi M, Pigeon P, Top S, Rhouma A, Aifa S, Rebai A, Vessières A, Plamont M A and Jaouen G. Evaluation of bactericidal and fungicidal activity of ferrocenyl or phenyl derivatives in the diphenylbutene series.J.Organomet. Chem., 2011, 696, 1038-48.

[15] Perjési P, Takács-Novák K, Rozmer Z, Sohár P, Bozak $\mathrm{R}$ and Allen T. Comparison of structure, $\log \mathrm{P}$ and $\mathrm{P}_{388}$ cytotoxicity of some phenyl and ferrocenyl cyclic chalcone analogues. Application of RP-TLC for $\log \mathrm{P}$ determination of the ferrocenyl analogues. Cent.Eur J.Chem., 2012, 10, 1500-05.

\section{How to cite this article:}

Ahmedi R, Lanez T. Estimating octanol/water partition coefficient for selected ferrocene derivatives using xlogpv2.0 approach. J. Fundam. Appl. Sci., 2016, 8(3), 1182-1192. 